\title{
P-0541- Effect of 12 weeks structured exercise training on Insulin resistance in Type 2 Diabetes Mellitus: A Pre-Post study
}

Mr. A.Sampath Kumar ${ }^{1}$,Dr. Arun G Maiya ${ }^{* 1}$,Dr. B.A.Shastry ${ }^{2}$,Dr. Vaishali. K ${ }^{1}$, Mr. Animesh Hazari ${ }^{1}$

1.Department of Physiotherapy, SOAHS, Manipal University, Manipal,

2.Department of Medicine, Kasturba Hospital, Manipal

Introduction

- Diabetes mellitus is a chronic metabolic disease characterized by chronic hyperglycemia which is associated with impaired carbohydrate, lipid, and protein metabolism. (Motahari-Tabari 2014)

- Type 2 diabetes is increasing rapidly around the world parallel to increase in the obesity.

- In 2011, an estimated 366 million people had diabetes (most of which is type 2) which is projected to increase $\mathbf{5 5 2}$ million by 2030. (Aune et.al., 2015)

- T2DM is characterized by elevated glucose levels in circulating blood, caused by impairment in glucose tolerance which is responsible for the development of insulin resistance $\&$ relative insulin deficiency

- IR impair the ability of muscle cells to take up \& store glucose ,triglycerides, which results in higher levels of glucose \& triglycerides circulating in blood

- Impaired glucose control \& IR are reported to be a risk factor for development of cardiovascular disease.

- Exercise and Physical activity have been considered as a cornerstone for the treatment and prevention of diabetes.

(Short et al., 2008)

- Need for the study: In Indian population, Insulin resistance is one of the strong reason for altered glycemic control, even though exercise training is found to be effective in glycemic control along with the standard medical care. There is a dearth of literature in the effectiveness of exercise training on insulin resistance in type 2 diabetes mellitus.

- Aim: To find out the effect of structured exercise program on insulin resistance by using Fasting insulin level and Homa-IR in T2DM.

\section{Materials and Methods}

Inclusion criteria: Aged 30-75 years who are with T2DM \& Oral hypoglycemic agent with or without Insulin therapy

Exclusion criteria: Type 1 diabetes mellitus, known case of Respiratory disease, Coronary artery disease, Neurological disorders, Musculoskeletal problems that would interfere with the exercise training

Tools: Stadiometer,Weighing scale, Bioelectrical impedence analyser, Skin fold caliper, Measuring tape, Motorized treadmill, Radio-telemetric heart rate monitor
Procedure:

- Total 17 participants were recruited. All participants were screened clinically \& biochemically and given a set of structured exercise program 3 times a week for 12 weeks along with standard medical care.

- The exercise protocol included warm-up by stretching and flexibility exercises for $10 \mathrm{~min}$. It mainly consisted of aerobic and resistance exercise like-brisk walking for $45 \mathrm{mins}$, weights for upper and lower body major muscle groups with maximum intensity $60 \%$ increase in heart rate and then stretching in the seated position for $10 \mathrm{~min}$.

- Resistance to insulin was assessed using Homeostasis Model Assessment of Insulin Resistance (HOMA-IR), Fasting insulin level and Fasting blood sugar.

\section{Results}

Table 1: Demographic Data

\begin{tabular}{|c|c|}
\hline Age in years & $59.23 \pm 8.38$ \\
\hline $\begin{array}{c}\text { Duration of Diabetes } \\
\text { in years }\end{array}$ & $10.82 \pm 7.82$ \\
\hline Body Mass Index & $26.64 \pm 4.09$ \\
\hline
\end{tabular}

Table 2: Pre \& Post changes

\begin{tabular}{|c|c|c|c|c|}
\hline Parameter & $\begin{array}{c}\text { Pre } \\
(\text { mean } \pm \text { SD })\end{array}$ & $\begin{array}{c}\text { Post } \\
(\text { mean } \pm \text { SD })\end{array}$ & $\begin{array}{c}\text { Pre-post } \\
(\text { mean } \pm \text { SD })\end{array}$ & P value \\
\hline $\begin{array}{c}\text { Fasting Insulin } \\
(\mu \mathrm{U} / \mathrm{ml})\end{array}$ & $21.20 \pm 12.13$ & $12.86 \pm 8.34$ & $8.34 \pm 6.60$ & $0.000^{*}$ \\
\hline $\begin{array}{c}\text { Homa- IR } \\
\text { Fasting blood } \\
\text { sugar } \\
(\mathrm{mg} / \mathrm{dl})\end{array}$ & $10.49 \pm 6.54$ & $5.18 \pm 4.8$ & $5.31 \pm 6.64$ & $0.005^{*}$ \\
\hline$p<0.05^{*}$ & $164.35 \pm 48.26$ & $127.29 \pm 21.59$ & $37.05 \pm 47.35$ & $0.005^{*}$ \\
\hline
\end{tabular}

\section{Conclusion}

From the current study findings we suggest that 12 weeks of structured exercise program training three times a week was effective on insulin resistance and glycaemic control in T2DM patients.

Acknowledgement: World Diabetes Foundation (WDF 15941) Diabetic foot care: Stepping Ahead
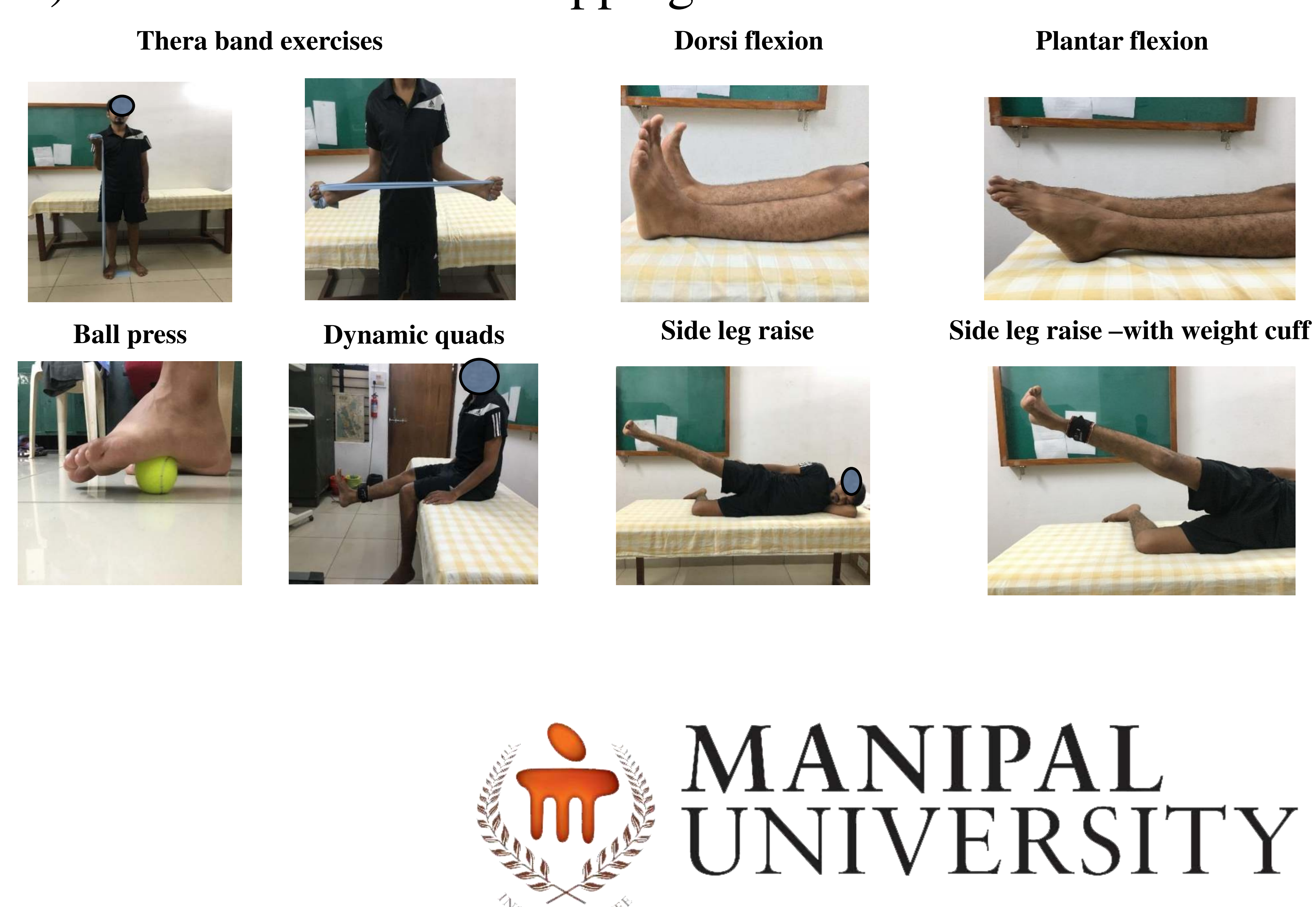